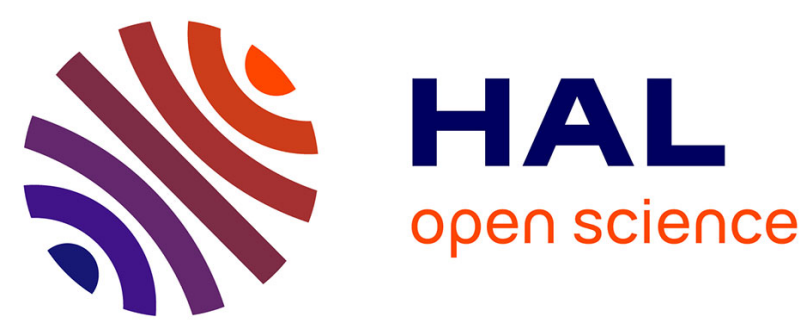

\title{
Experimental investigation of thermal vehicular environment during the summer season
}

Paul Danca, Florin Bode, Amina Meslem, Cristiana Croitoru, Mihnea Sandu, Ilinca Nastase, Catalin Lungu, Loretta Batali

\section{- To cite this version:}

Paul Danca, Florin Bode, Amina Meslem, Cristiana Croitoru, Mihnea Sandu, et al.. Experimental investigation of thermal vehicular environment during the summer season. Science and Technology for the Built Environment, 2022, 28 (1), pp.42-54. 10.1080/23744731.2021.1911157 . hal-03227330

\section{HAL Id: hal-03227330 \\ https://hal.science/hal-03227330}

Submitted on 20 Sep 2021

HAL is a multi-disciplinary open access archive for the deposit and dissemination of scientific research documents, whether they are published or not. The documents may come from teaching and research institutions in France or abroad, or from public or private research centers.
L'archive ouverte pluridisciplinaire HAL, est destinée au dépôt et à la diffusion de documents scientifiques de niveau recherche, publiés ou non, émanant des établissements d'enseignement et de recherche français ou étrangers, des laboratoires publics ou privés. 


\title{
Experimental investigation of thermal vehicular environment during the summer season
}

Paul Danca ${ }^{1}$ Florin Bode ${ }^{1,2}$ Amina Meslem ${ }^{3}$ Cristiana Croitoru ${ }^{1}$ Mihnea Sandu ${ }^{1}$ Ilinca Nastase $^{1 *}$, Catalin Lungu ${ }^{1}$ Loretta Batali ${ }^{1}$

* Auteur correspondant

1 - UTCB - Technical University of Civil Engineering of Bucharest = Université Technique de Génie Civil de Bucarest

2 - UTCN - Universitatea Tehnica din Cluj-Napoca

3 - LGCGM - Laboratoire de Génie Civil et Génie Mécanique

\begin{abstract}
Thermal comfort evaluation for vehicle occupants is very complicated due to the transient nature and non-uniformity of the vehicle interior. The thermal sensation of an automobile occupant is affected by the surrounding environment. Furthermore, the existing standard was developed for steady state and controlled conditions and it utilizes three evaluation indices, some of which are not adapted for this complex environment. In this article, the three standardized indices are compared in terms of thermal comfort, for a passenger vehicle in summer season. The results show that the mean values of the PMV/PPD model calculated at a single point with Comfort Sense equipment are far from the TSV mean values which were collected in questionnaires, while the $t_{e q}$ index which was calculated with an advanced thermal manikin are closer to the TSV comfort votes. This may be explained by the fact that the TSV and $t_{e q}$ consider the sensation for each body part at the local level. For a correct evaluation of the thermal comfort in non-uniform and transient environments like in vehicles, it is not enough to measure a single point.
\end{abstract}

Keywords: thermal comfort; vehicle environment; summer season; experimental investigation; thermal manikin 


\section{Introduction}

Designers from the automotive industry have started to pay attention to the passengers comfort during the last decades with the lowering of production costs and with the increased safety of vehicles. Furthermore, in the past, the design approach of the Heating Ventilation and Air Conditioning (HVAC) systems was extensively based on methods used in the field of building systems. Unlike buildings' indoor environment, the vehicular ambient is dominated by thermal transient conditions the strongly non-uniform thermal environment, high air speeds values of localized flows (unlike the diffuse air movement from the buildings) with high turbulence or low frequency fluctuations, the solar heat flux and the intensity of the solar radiation, the radiative flux occurring from the in-cabin surfaces and the much higher levels of relative humidity compared to the buildings, etc.. Accordingly, one particular aspect is represented by the high values of the air velocity compared to other occupied enclosures, which leads to intense localized air flows that might highly fluctuate in the presence of an automatically controlled air conditioning system (Dehne et al. 2018; Psikuta et al. 2017).

A secondary aspect is related to the interior surface materials and to the temperatures values which have a direct impact on the mean radiant temperature value. Surface temperatures are mostly influenced by solar radiation. Besides, considering the case of the human body parts exposed to the direct solar radiation, it was demonstrated that their thermal state changes with direct implication on the thermal comfort of the passenger. The air temperature inside the car might reach $72^{\circ} \mathrm{C}$ in summer, even when the outdoor temperature is $34^{\circ} \mathrm{C}$ and the solar radiation is around $800 \mathrm{~W} / \mathrm{m}^{2}$ according to (Grundstein, Meentemeyer, and Dowd 2009). During these periods, the car ventilation and the air conditioning systems will hardly control the vehicle compartment thermal environment.

The physiological differences between the passengers due to age, sex, state of health, cultural differences that would result in various clothing approaches should be added to the environmental physical parameters stated before. The psychological component represents even a greater supplementary challenge in this case knowing that drivers' attention could be associated with a thermal sensation which may differ for each subject (Shin et al 2017). The driver will obviously come across situations that impose requirements over and above those represented by routine operations. He must perceive a potential hazard becoming consciously aware of it and then diagnose it. The driver must then carry out the required action when a response is needed. In most driving situations events are happening at a slow rate and there is enough time available to react. However, the driver can sometimes be under stress, not being able to react because of too many stimuli and then the possibility of error increases (Bonnett 2006). In this context, a direct connection between drivers' thermal sensation and his focus on the driving tasks could be established in the literature (Feher 1993; Walgama et al. 2006). All these parameters are linked with unknown dependencies (Alahmer et al.

\section{ACCEPTED MANUSCRIPT}


2011).

A large number of research studies are addressing the subject of thermal comfort related to the inside-cabin environment. The available literature is dispersed around those papers dealing with the observation of the environmental conditions inside the vehicle that might affect the human thermal comfort (Lee 2015; Konstantinov and Wagner 2016; Bode et al. 2017; Danca et al. 2017, Danca et al. 2018) and those concerning the human's response and the perception of its interaction with the environment (Rugh and Bharathan 2005; Fojtlín et al. 2017; Mao, Wang, and Li 2018; Zhou, Lai and Chen 2019).

The current investigation might be placed in the second category of research studies. This paper is focused on the transient non-uniform environment inside the automobile compartment using an experimental investigation in a real car during the summer season without solar irradiation. The results are part of a larger experimental and numerical study, dedicated to developing knowledge regarding the correlation between air distribution strategies inside vehicles and thermal comfort of their passengers.

\section{Experimental set-up}

A Renault Megane II year of fabrication 2006 having a manual ventilation/conditioning system was used for the experimental study. The vehicle was placed inside a building annex of the Technical University of Civil Engineering of Bucharest (see Figure 1). This choice was related to the need to achieve a much slower variation of environmental parameters, especially of the air temperature and to decouple the inside-cabin conditions from the solar radiation effect.

The experimental campaigns were carried in the summertime during two days with similar exterior meteorological conditions. The air temperature inside the building where the automobile was placed was monitored using thermocouples. The average temperature value was $40^{\circ} \mathrm{C}$. The mean air temperature variation during the experimental campaigns is represented in Figure 2.

The engine was turned on for 30 minutes before the measurement sessions as stated in ISO 14505-3 (2006). 

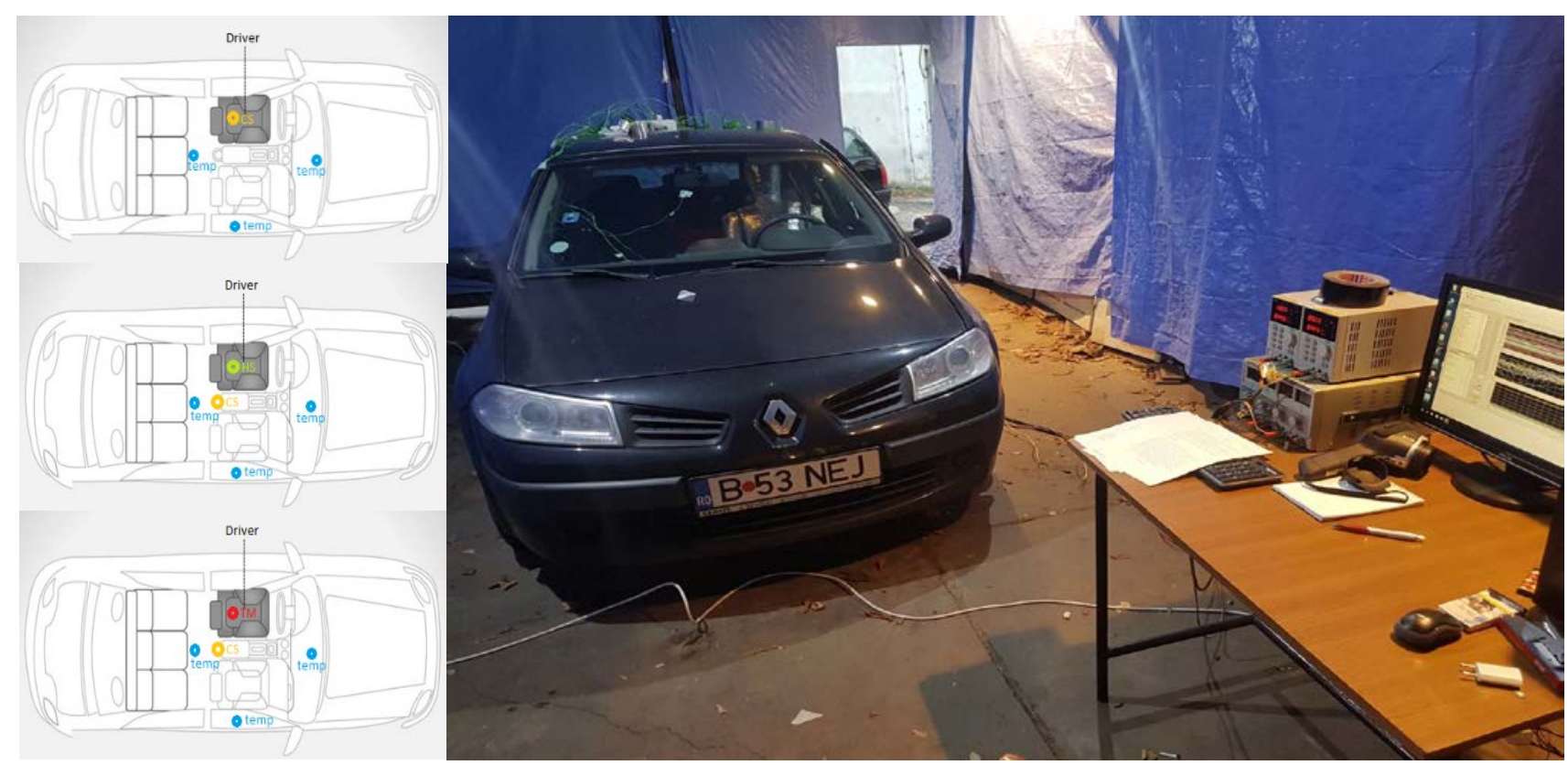

Fig. 1. Set-up in the experimental hall

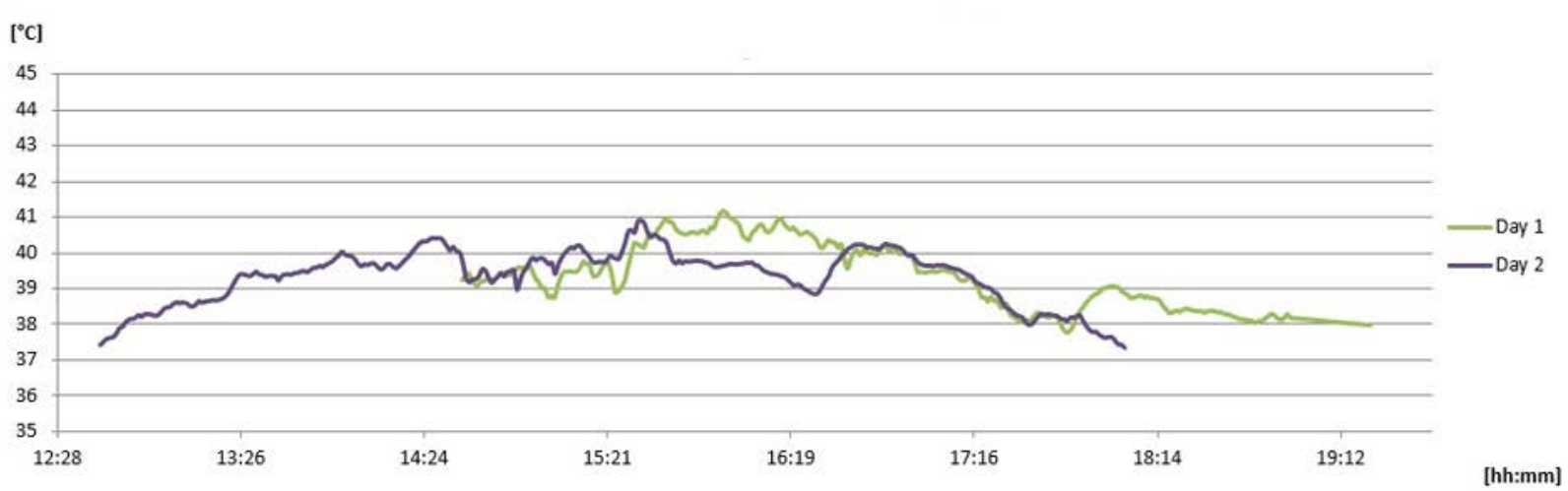

Fig. 2. Air temperature variation inside the experimental hall

A grid of measurement points was created inside the car cabin and on the inside surfaces to record the temperature values. 27 k-type thermocouples were used, together with three data loggers from Ahlborn (two Almemo 710 with 10 sensor connecting ports available for each one, and one Almemo 2890-9 with 9 sensor connecting ports available). The thermocouples were placed as displayed in Figure 3.

Fifteen thermocouples were placed in the locations corresponding to main parts of human body (head, chest, abdomen, knee, and ankles) that are sensible to the draft sensation (Figure 3 a). Three thermocouples were placed at the inlets: the first one inside the central diffuser, the second one inside the left side diffuser and the third one inside the right-side diffuser. Another nine thermocouples were placed on the inside surfaces of the car cabin: on the dashboard, on the windshield, on the lateral windows, on the ceiling, on the floor, on the top of the trunk lid and on the rear window (Figure 3b). The technical specifications of the thermocouples are given in Table 1 in 
terms of measurement range and accuracy. Prior to the experimental campaign the thermocouples were calibrated using a thermostatic bath Lauda Eco Silver.

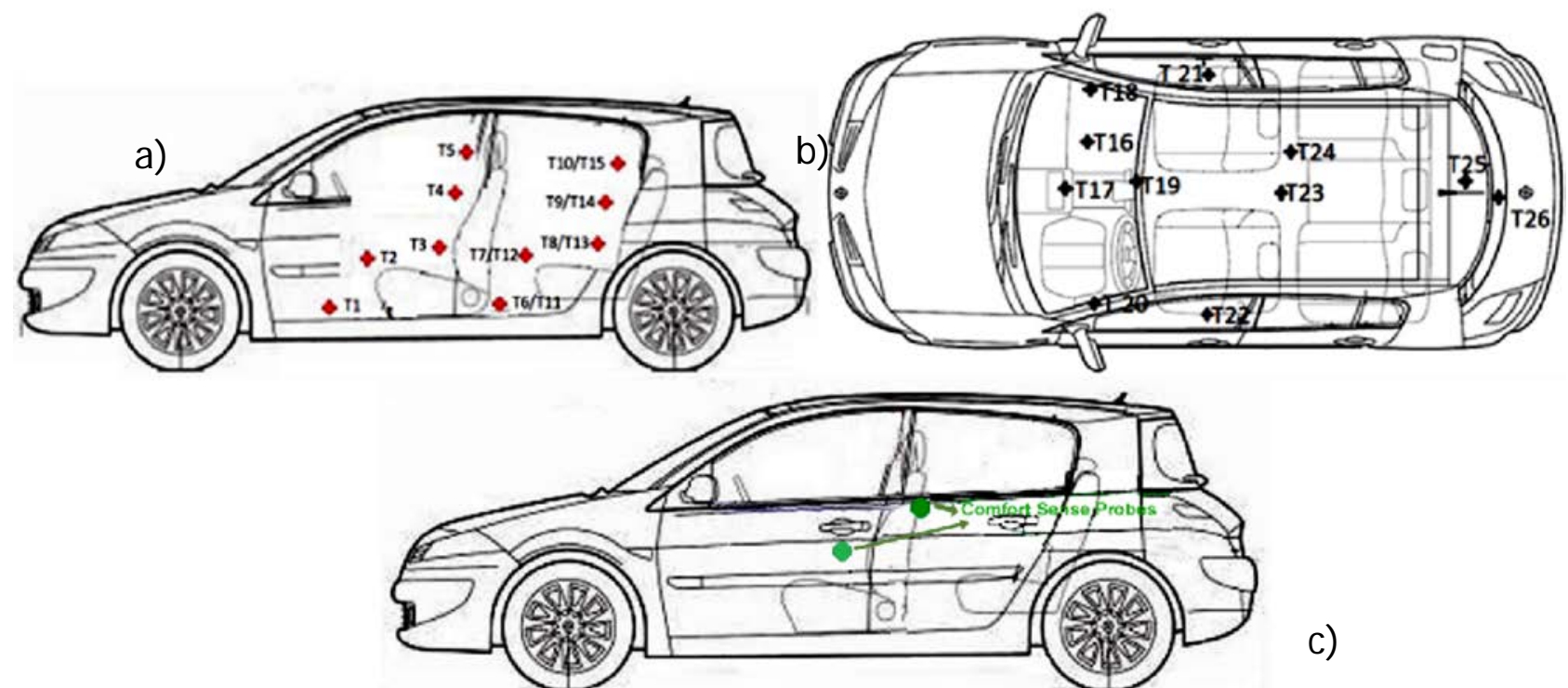

Fig. 3. Locations of the measurement equipment inside the experimental vehicle: a) positions of the passenger body parts, b) air diffusers and interior surfaces, c) position of the Comfort Sense system

The complete evaluation of the thermal comfort inside the vehicle cabin (Table 4) was performed following the guidelines of all the three parts of ISO 14505 "Evaluation of thermal environments in vehicles": 1. Principles and methods for assessment of thermal stress; 2. Determination of equivalent temperature; 3. Evaluation of thermal comfort using human subjects (ISO 14505-3 2006; ISO 145052 2006; ISO 14505-1 2007).

Table 1 Technical specifications of the employed measurement equipment

54 T33 Draft

Probe
54T37 Relative

Humidity Probe
54T38 Operative

Temperature Probe
Almemo Datalogger thermocouples K-

type
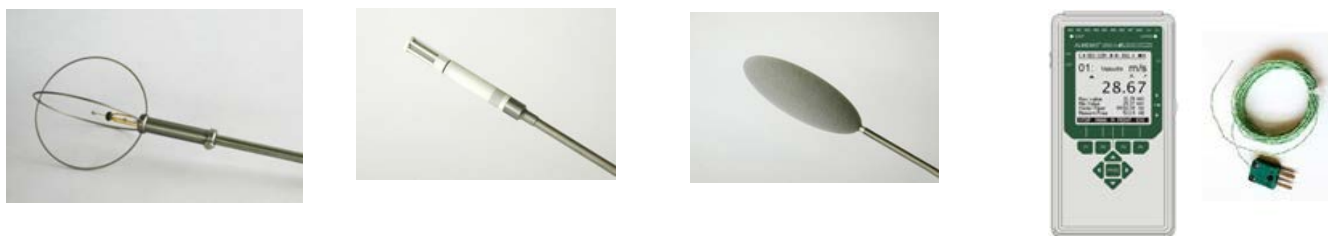

Range

0.05 to $5 \mathrm{~m} / \mathrm{s}$

$-20^{\circ} \mathrm{C}$ to $+80^{\circ} \mathrm{C}$

0 to $100 \%$

0 to $+45{ }^{\circ} \mathrm{C}$

-270 to $+1372{ }^{\circ} \mathrm{C}$

Accuracy

$1.5 \%$

$\pm 0.2 \mathrm{~K}$

$\pm 0.1^{\circ} \mathrm{C}$ 
In the first part of the standard - ISO 14505-1 2007 a method based on the models developed by Fanger for buildings, i.e., the Predicted Mean Vote (PMV) and the Predicted Percentage of Dissatisfied (PPD) it is proposed. In this study, PMV and PPD indexes were evaluated directly using an integrated measurement system called ComfortSense (Dantec Dynamics). The system is composed of a draft probe, a relative humidity probe and an operative temperature probe (Table 1). The draft probe is composed by an omnidirectional, hot film, a velocity probe, and a thermistor. The Comfort Sense system was placed either in the center of the car, either in the place of the driver (figure 3c). Its probes were mounted on a tripod. The distances between each probe and the cabin surfaces were different depending on their position (i.e., center of the cabin or driver's place). When the Comfort sense system was placed on the center of the car, the draft probe and the operative temperature probe were aligned with the median longitudinal plane of the car, at around $0.7 \mathrm{~m}$ from the side windows, and $0.5 \mathrm{~m}$ from the rear seat. Both probes were mounted at a height of $0.6 \mathrm{~m}$ from the floor, corresponding to the abdomen position of a sitting person. The operative temperature probe was fixed at an angle of $30^{\circ}$ from the vertical direction. The relative humidity probe was set in vertical position at a hight of $0.5 \mathrm{~m}$ from the floor. When the Comfort sense system was placed on the driver's place, the draft probe and the operative temperature probe were aligned with a longitudinal plane passing through the steering wheel, at around $0.35 \mathrm{~m}$ from the front left-side window, and $1.05 \mathrm{~m}$ from the front right-side window, $0.3 \mathrm{~m}$ from the driver's seat back and 0,35 $\mathrm{m}$ to the steering wheel. Both probes were mounted at a height of $0.6 \mathrm{~m}$ from the floor. The operative temperature probe was fixed as previously, at an angle of $30^{\circ}$ from the vertical direction. The relative humidity probe was also setin vertical position at a hight of $0.5 \mathrm{~m}$ from the floor.

The technical specifications of the Comfort Sense system (Dantec Dynamics 2009) are given in Table 1 in terms of measurement range and accuracy, for each probe. The system has a valid calibration certificate from the supplier. However, the response of omnidirectional velocity probe is verified periodically using the Hot-Wire calibrator from Dantec and a tool used for directional calibration of the hot-wire probes.

Table 2 Air flow parameters for the three steps of the mechanical ventilation system

\begin{tabular}{|c|c|c|c|c|c|c|c|c|c|}
\hline \multirow{2}{*}{$\begin{array}{c}\text { Ventilation } \\
\text { step }\end{array}$} & \multicolumn{3}{|c|}{ Flow rate $[\mathrm{kg} / \mathrm{s}]$} & \multicolumn{3}{c|}{ Temperature $\left[{ }^{\circ} \mathrm{C}\right]$} & \multicolumn{3}{c|}{ Mean velocity [m/s] } \\
\cline { 2 - 11 } & $\begin{array}{c}\text { left } \\
\text { diffuser }\end{array}$ & $\begin{array}{c}\text { central } \\
\text { diffusers }\end{array}$ & $\begin{array}{c}\text { right } \\
\text { diffusers }\end{array}$ & $\begin{array}{c}\text { left } \\
\text { diffuser }\end{array}$ & $\begin{array}{c}\text { central } \\
\text { diffusers }\end{array}$ & $\begin{array}{c}\text { right } \\
\text { diffusers }\end{array}$ & $\begin{array}{c}\text { left } \\
\text { diffuser }\end{array}$ & $\begin{array}{c}\text { central } \\
\text { diffusers }\end{array}$ & right diffusers \\
\hline V1 & 0.0057 & 0.016 & 0.0083 & 11.5 & 11,0 & 4.0 & 1.66 & 3.29 & 4.85 \\
\hline V2 & 0.0114 & 0.0316 & 0.0152 & 13.2 & 14.0 & 9.8 & 0.86 & 1.58 & 2.50 \\
\hline V3 & 0.0194 & 0.0466 & 0.0241 & 17.1 & 18.0 & 15.9 & 0.60 & 1.19 & 2.02 \\
\hline
\end{tabular}


Table 3 Surface temperatures of the thermal manikin (I SO 14505-2 2006)

\begin{tabular}{|c|c|c|c|c|c|c|c|c|}
\hline Region & Head & Torso & Arms & Forearms & Hands & Lower abdomen and thighs & Shins & Feet \\
\hline $\mathrm{T}\left[{ }^{\circ} \mathrm{C}\right]$ & 36 & 34.5 & 33 & 32 & 30 & 32.5 & 30 & 27 \\
\hline
\end{tabular}

The second part of the standard, ISO 14505-2 (2006), proposes another experimental procedure based on the evaluation of the equivalent temperature index $\left(t_{e q}\right)$ using different approaches, including thermal manikins (Cheong et al. 2006; Causone et al. 2010; Barna and Bánhidi 2012; Krajč́́k, Simone, and Olsen 2012; Melikov, Ivanova and Stefanova 2012). The local equivalent temperature is related either to a number of body parts, either to one single body part and it is based on the measurements for one zone or for more zones of a human-shaped heated sensor, at the full scale of the human body. An advanced thermal manikin (Ursu et al. 2018) was employed in the study carried out in this paper (Figure 4).
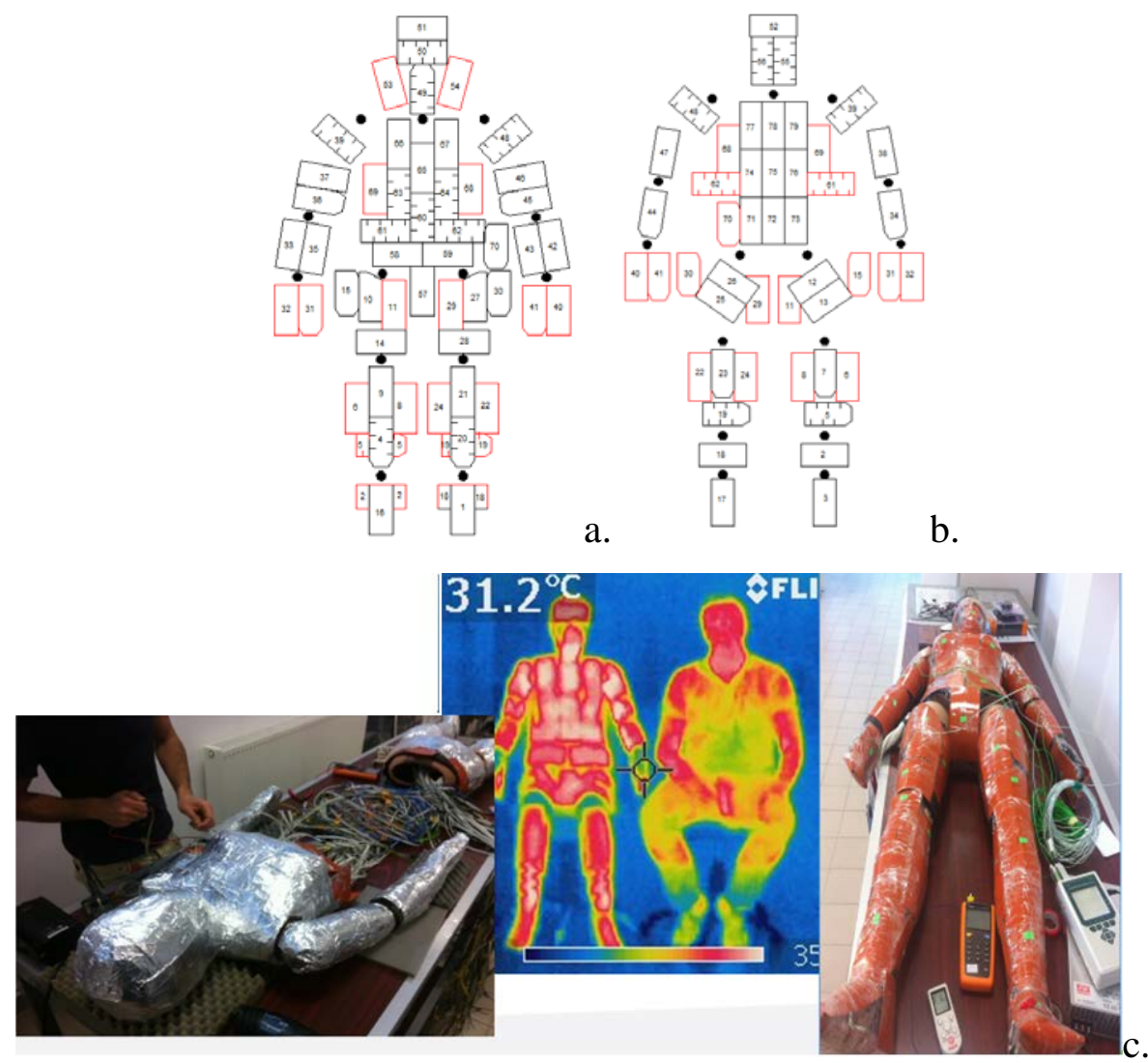

Fig. 4. Thermal manikin employed in this study: distribution of the heating elements on the individually anatomic zones controlled (red patches are corresponding to the other side of the manikin): a) front view, b) back view, c) general appearance and comparison with the anatomic distribution of skin temperature of a human

A thermal manikin is associated with the local heat balance of some defined zones. The thermal manikin used in this study was conceived at the Building Services Engineering Faculty (CAMBI Research Center) and it has an advanced human anatomic shape, with 79 independent active zones,

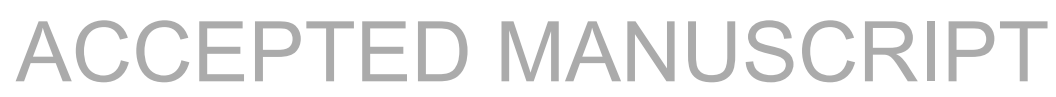


395 temperature sensors and its own in-house software for data acquisition and control of the body zone’s surface temperature (Ursu et al. 2018). If we compare to classical measurement systems - like the aforementioned comfort meter which offer the possibility of estimating the global PMV, a thermal manikin gives us the advantage of a local scale through its different segments. The segments, that are heating and measuring circuits, represents the body parts. In this way a local sensation can be foreseen through the equivalent temperature or through a derived local PMV.

The thermal manikin is equipped with 395 TSic T501 thermistors, 5 sensors for each of its 79 zones. Each sensor position has been established using an infrared thermal camera Flir E40, in order to have the same mean temperature value of the five sensors with the mean value of the zone. TSic T501 thermistors have an accuracy predicted by the manufacturer of $\pm 0.1 \mathrm{~K}$ in a range of $40 \mathrm{~K}$. Every thermistor has been calibrated using the thermostatic bath Lauda Eco Silver in the range 5- $45^{\circ} \mathrm{C}$.

The thermal manikin itself was calibrated in a climatic chamber in order to find the relationship between surrounding temperature value and heat losses. The heat transfer coefficients for both anatomic and uniform temperature distribution with $34^{\circ} \mathrm{C}$, in both seating and standing positions were compared to literature data for other thermal manikins (Danca 2018) finding similar values. However, the thermal loss coefficient of different manikins is usually different, given the variety of constructive modes and only their magnitude should be compared.

The air temperature value was the same as the mean radiant temperature value of $24^{\circ} \mathrm{C}$ during the calibration of the manikin. The first calibration was performed using the naked manikin at a uniform surface temperature of $34^{\circ} \mathrm{C}$ in the center of the climatic chamber. The second calibration was performed for the anatomic distribution of the temperature. No vertical temperature differences were observed in the chamber during each calibration process. The relative humidity was monitored and in the interval $50 \pm 2.5 \% \mathrm{RH}$. The mean air velocity in the proximity of the manikin (but not in its convective plume) displayed mean values $0.1 \pm 0.02 \mathrm{~m} / \mathrm{s}$ using the omnidirectional velocity probe from the Comfort Sens system, but installed in another setup using a multichannel CTA system from Dantec.

Table 4 Experimental methods and corresponding thermal indexes

\begin{tabular}{|c|c|c|c|}
\hline $\begin{array}{c}\text { Ventilation } \\
\text { step }\end{array}$ & Sessions 1-9 & Session 10 & Session 11 \\
\hline V1 & $\begin{array}{c}\text { TSV from human subjects placed } \\
\text { driver seat and PMV from CS } \\
\text { placed in the middle of car }\end{array}$ & $\begin{array}{c}t_{e q} \text { from manikin placed on driver seat and } \\
\text { PMV from CS placed in the middle of car }\end{array}$ & $\begin{array}{c}\text { PMV from the CS placed on } \\
\text { the driver seat }\end{array}$ \\
\hline V2 & $\begin{array}{c}\text { TSV from human subjects placed } \\
\text { driver seat and PMV from CS } \\
\text { placed in the middle of car }\end{array}$ & $\begin{array}{c}\text { teq from manikin placed on driver seat and } \\
\text { PMV from CS placed in the middle of car }\end{array}$ & $\begin{array}{c}\text { PMV from the CS placed on } \\
\text { the driver seat }\end{array}$ \\
\hline V3 & $\begin{array}{c}\text { TSV from human subjects placed } \\
\text { driver seat and PMV from CS } \\
\text { placed in the middle of car }\end{array}$ & $\begin{array}{c}t_{e q} \text { from manikin placed on driver seat and } \\
\text { PMV from CS placed in the middle of car }\end{array}$ & $\begin{array}{c}\text { PMV from the CS placed on } \\
\text { the driver seat }\end{array}$ \\
\hline
\end{tabular}


The anatomical temperature distribution on the surface of the thermal manikin was considered in this study using the indications from ISO 14505-2 (2006) (table 3).

The method described in the third part of the standard ISO 14505-3 (2006), implies human subjects, in order to estimate a value of the Thermal Sensation Vote (TSV), issued from survey questionnaires filled in by samples of volunteers. The TSV index, represents a corresponding measure of the PMV index deduced through experimental methods (the comfort meter for instance). The questions composing the questionnaire used in this study was chosen with regards to ISO 14505-3 (2006) and ISO 10551 (1995) which covers the construction and use of thermal sensation scales and proposes a set of specifications on direct experts' assessment of thermal comfort/discomfort expressed by persons subjected to various degrees of thermal stress.

The survey was conducted following the demands of the standard ISO 14505-3 (2006) and knowing that a minimum sample of 8 persons is required by this standard. The nine human subjects were aged between 27 and 49 years, 7 of them men and 2 of them women. Each measurement set with human subjects was completed in 45 minutes, respectively 15 minutes for each of the three steps of the fan speed controller corresponding to V1, V2 and V3 (table 2, figure 5). During the first 15 minutes, the ventilation system was set on the step I (V1), the following 15 minutes it was set on step II (V2), and during the last 15 minutes it was set on step III (V3). The subjects were asked to take the drivers' seat in the running engine car placed in the experimental hall. Each surveyed person had been given a set of 12 questionnaires to fill-in during the entire session of 45 minutes. They were instructed to fill-in the first questionnaire at the very next moment after entering the car. Each of the following questionnaires was filled-in at intervals of 5 minutes. They were instructed to change the velocity step after 15 minutes and to fill-in additional questionnaires right after the change of the velocity step. A total number of 108 questionnaires were filled-in during the study.

It has been shown in the literature that the gender and the age have a major impact on thermal sensations. The thermal manikin used in this study is an instrument that brings the advantage of the local assessment of the thermal comfort. The zoning of the body segments offers the possibility of reproducing the human body with its anatomic distribution of the skin temperatures and uses it as a measurement equipment and as a detailed and precise heat source inside a physical model of a real thermal enclosure (such as an office, a car etc). The thermal manikin used in this study relies on the control of the surface temperatures and has the possibility to introduce different set point values for each segment. This means that it can reproduce the body of different type of categories of persons (i.e. older, younger, sick, etc.). For example, the thermal manikin it has been originally developed to offer the possibility to simulate patients in an operating room.

\section{ACCEPTED MANUSCRIPT}



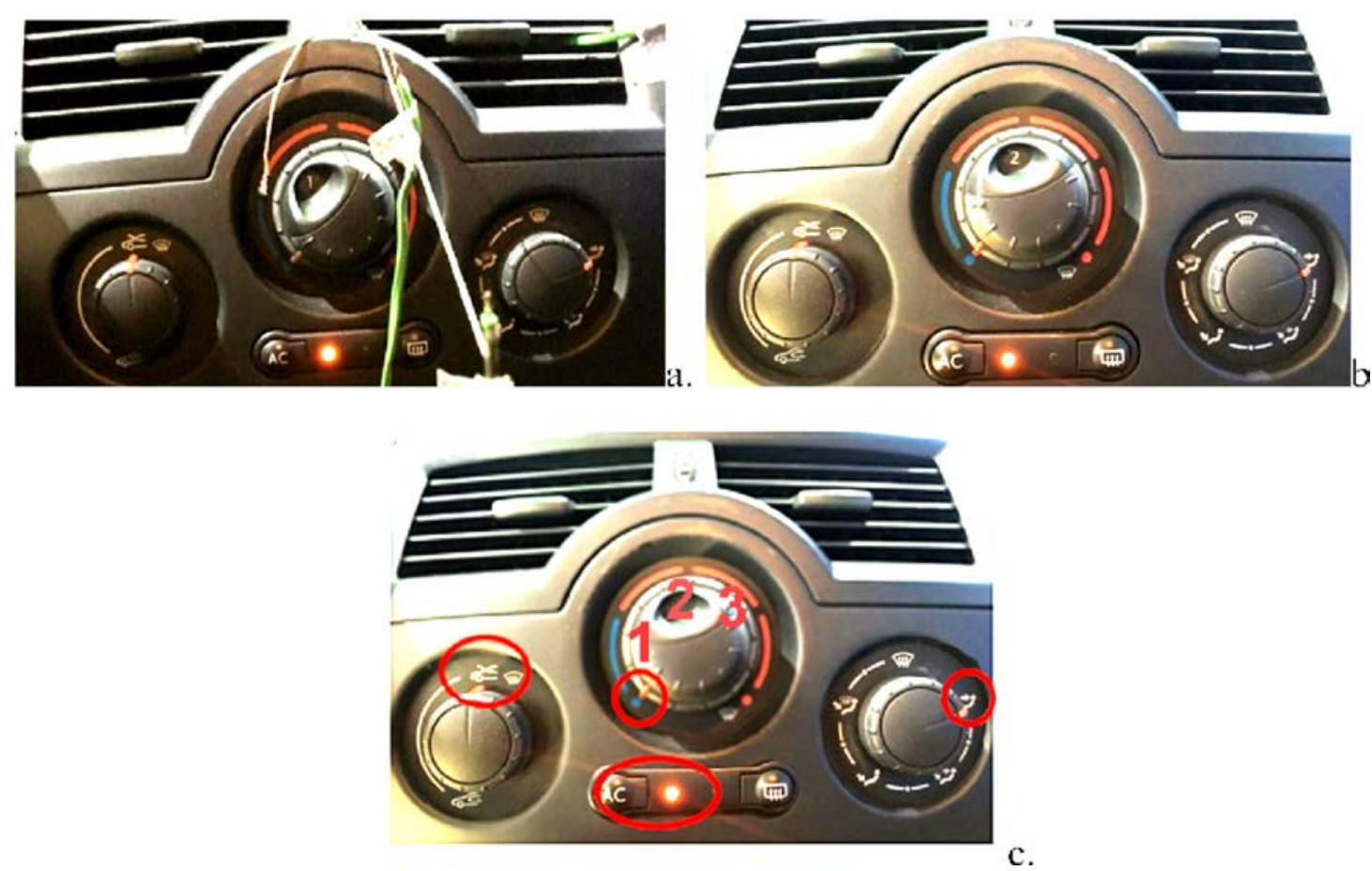

Fig. 5. Setup of the three position of the ventilation/cooling system a) V1, b) V2, c) V3

However, three experimental procedures were compared in this study, all described in the ISO 14505 standard, that are not directly considering the age and the gender. Considering this case, the PMV and the $t_{e q}$ represent a hypothetical standardized person which is neither a woman nor a man. Nevertheless, the human subjects were different, and the observed dispersion of their responses is caused also by gender and age differences. This conclusion demonstrates the limitations of each standardized approach.

For the three types of experimental approaches, a total number of 11 measurement sets were carried out (table 2), each of them lasting 45 minutes. Some photographs of the experimental set-ups for each of the experimental method are shown in figure 6. The thermal manikin and the Comfort Sense system were placed on the driver place for two measurements sets cases (Danca et al 2019). For the other nine measurement sets cases, there was a human subject placed on the driver place. and the Comfort Sense was placed in the centre of the car. 

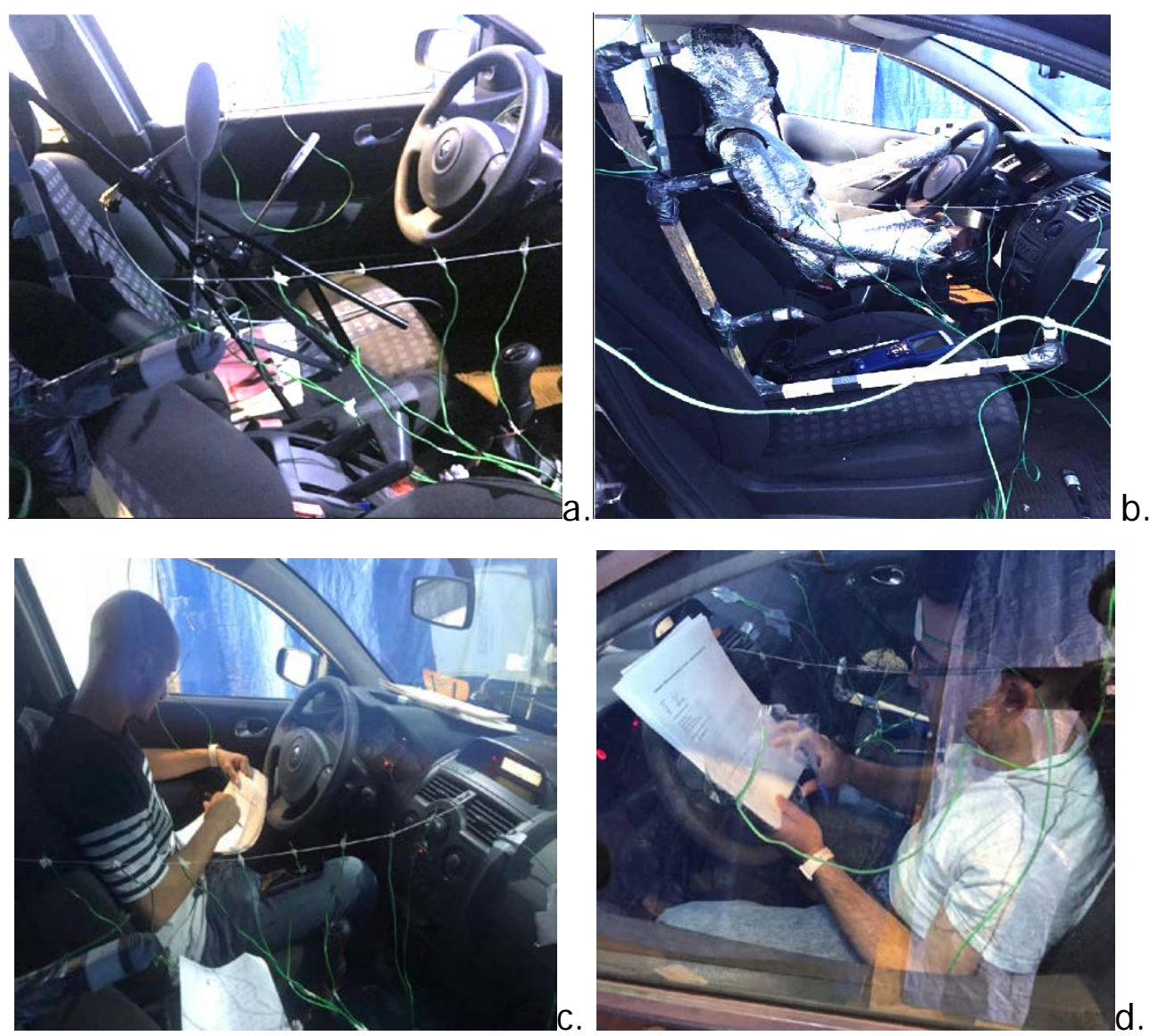

Fig. 6. Photographs from the experimental campaign: a) Comfort Sense measurements, b) Thermal manikin measurements, c, d) Human subjects measurements

The cooling system was turned on during all the measurement sessions. Cooled air was introduced in the cabin only through the front dashboard diffusers shown in Figure 7a. All the other diffusers were set in closed position using the dedicated vanes. The dashboard diffusers were fully open, and the airflow was directed normally to the inlet surface for all the studied cases. The ducting system for the dashboard diffusers is shown in Figure.7b.

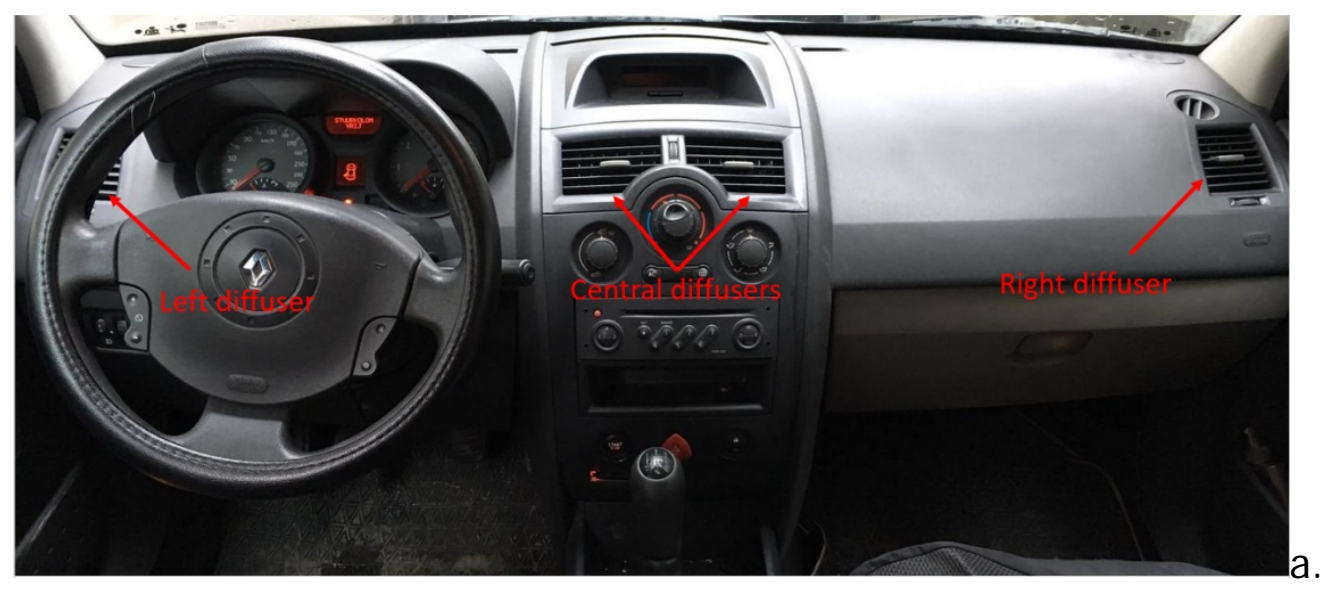




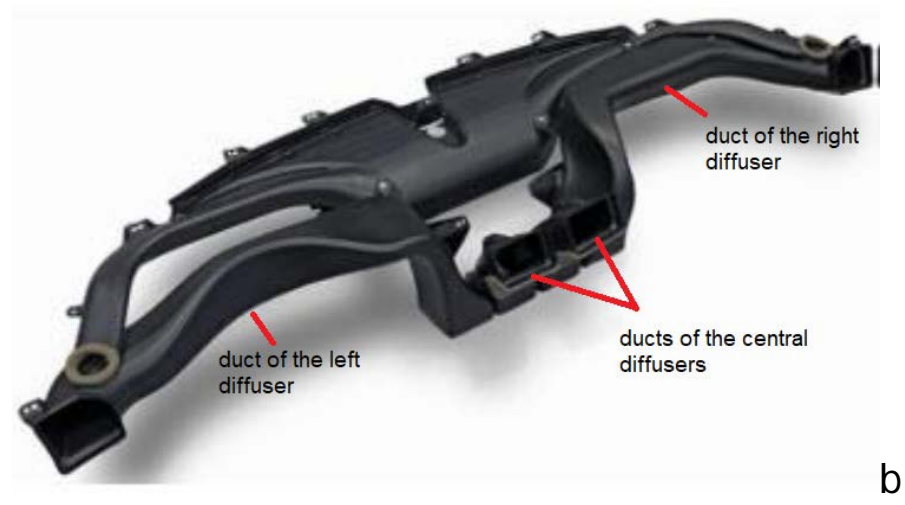

Fig. 7. a. Image of the dashboard with nomination of the air diffusers b. Ducting system for the dashboard diffusers

\section{Results and discussions}

The results obtained using the three standardized methods and a discussion based on their comparison are presented in this chapter.

Figure 8 shows the evolution of the temperature of the supplied air in the vehicle cabin for the three considered airflow values (V1, V2, V3), corresponding to the three positions of the fan speed controller (I, II, III), respectively for the right, center and left diffusers (Figure 7a).

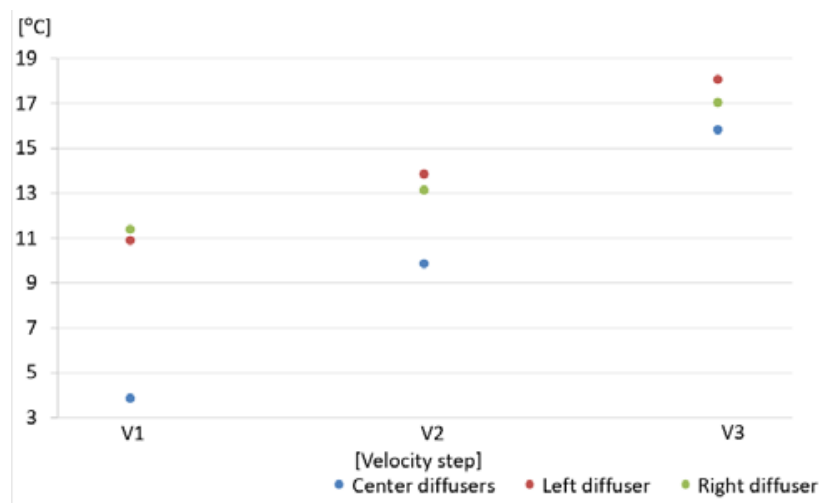

Fig. 8. Evolution of the supply air temperature from left, right, and central diffusers as a function of the fan speed controller

With the increasing of the air flowrate, it can observe that the air temperature at the exit plane of the diffusers is increasing. There are differences among the recorded temperature values between the right diffuser and the central or the left diffusers for each of the steps of the fan speed controller. This temperature difference must be correlated with the values of the mass flow rates from the table 2 for each diffuser and each step of the fan controller. The asymmetry in the mass flow rate and temperature distribution for the three types of diffusers is due to the ducting system that transports the cooled air from the ventilation/conditioning unit to each of the diffusers. The cooled air passes through the ducts that brings it to the dashboard, that have different lengths and different shapes. The central diffusers have very short ducts $(0.2 \mathrm{~m})$, while the side ducts are twice as longer $(0.5 \mathrm{~m})$. At the 
same time, the mass flow rate of the central diffusers is three times higher than for the side diffusers. The observed differences of temperature in Figure 8 are however related to the asymmetry of the side ducts. The left duct which supplies air to the left diffuser (driver side) has a cross section that is flattened compared to the duct from the right (Figure $7 \mathrm{~b}$ ), due to the dashboard panel and to the steering wheel.

Mean values of the air temperature in the center of the cabin and for the interior surfaces are presented in Figures 9 and 10. They are also depending of the ventilation airflows. The air temperature value recorded in the centre of the cabin presents an important decrease from $\mathrm{V} 1$ to $\mathrm{V} 2$ with $5.5^{\circ} \mathrm{C}$ and afterwards remains constant for V3. This could be explained by a better mixing of the three jet flows with the ambient air. Indeed, for the first position of the fan speed controller the mass flow rate is very low, and the airflow is not reaching the rear part of the vehicle cabin. This is confirmed by the evolutions of the temperatures on the interior surfaces for which the values are dispersed in a smaller range for the case corresponding to V3.

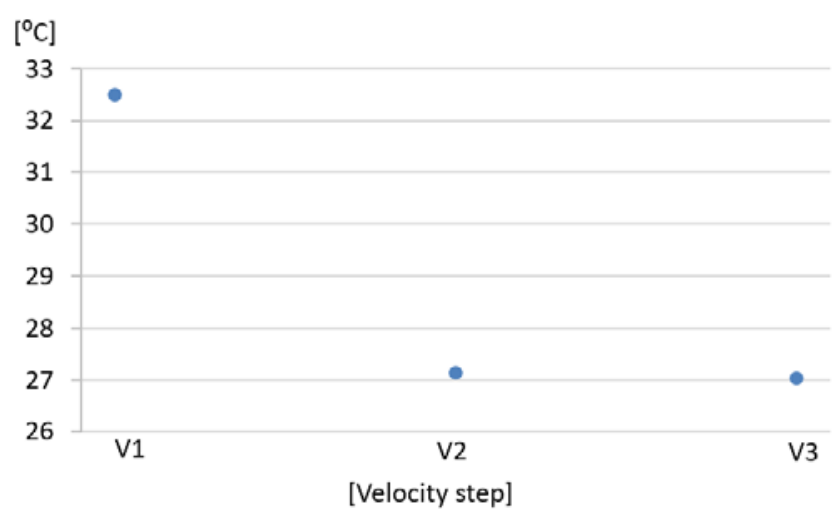

Fig. 9. Evolution of the air temperature in the center of the car cabin as a function of the fan speed controller

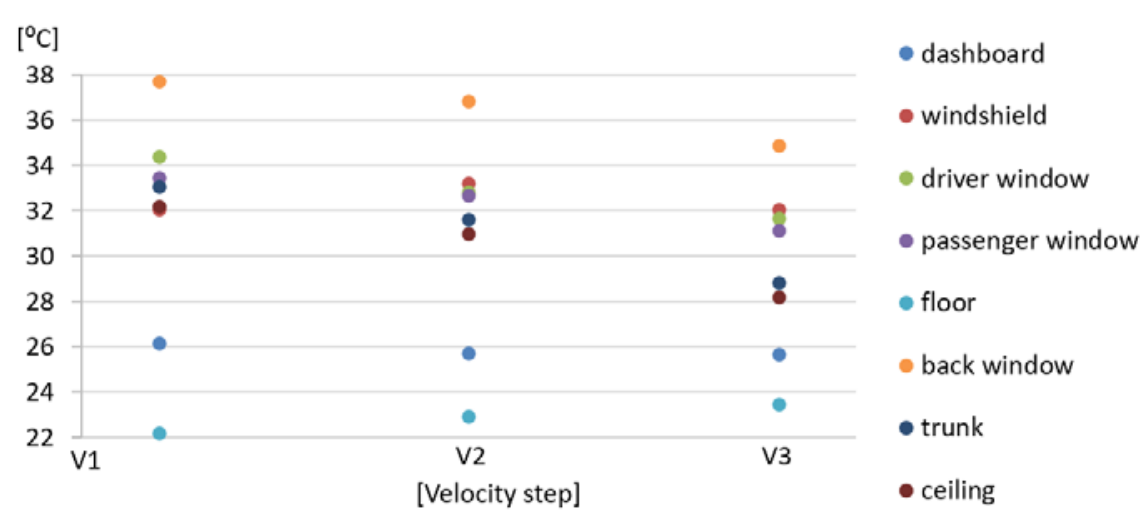

Fig. 10. Evolution of the air temperatures on different interior surfaces as a function of the fan speed controller

The results assessed with the thermal manikin are presented in Figure 11 on a diagram with different comfort levels for each body part, noted from 1 to 5.1 is corresponding to too cold, 2 is for cold but comfortable, 3 for neutral, 4 for warm but comfortable, 5 for too 
hot. To each comfort level on this scale are corresponding differed ranges of the equivalent temperature ( $\left.t_{e q}\right)$ values that specific for each body part. This ranges are presented in the standard ISO 14505-2 (2006).

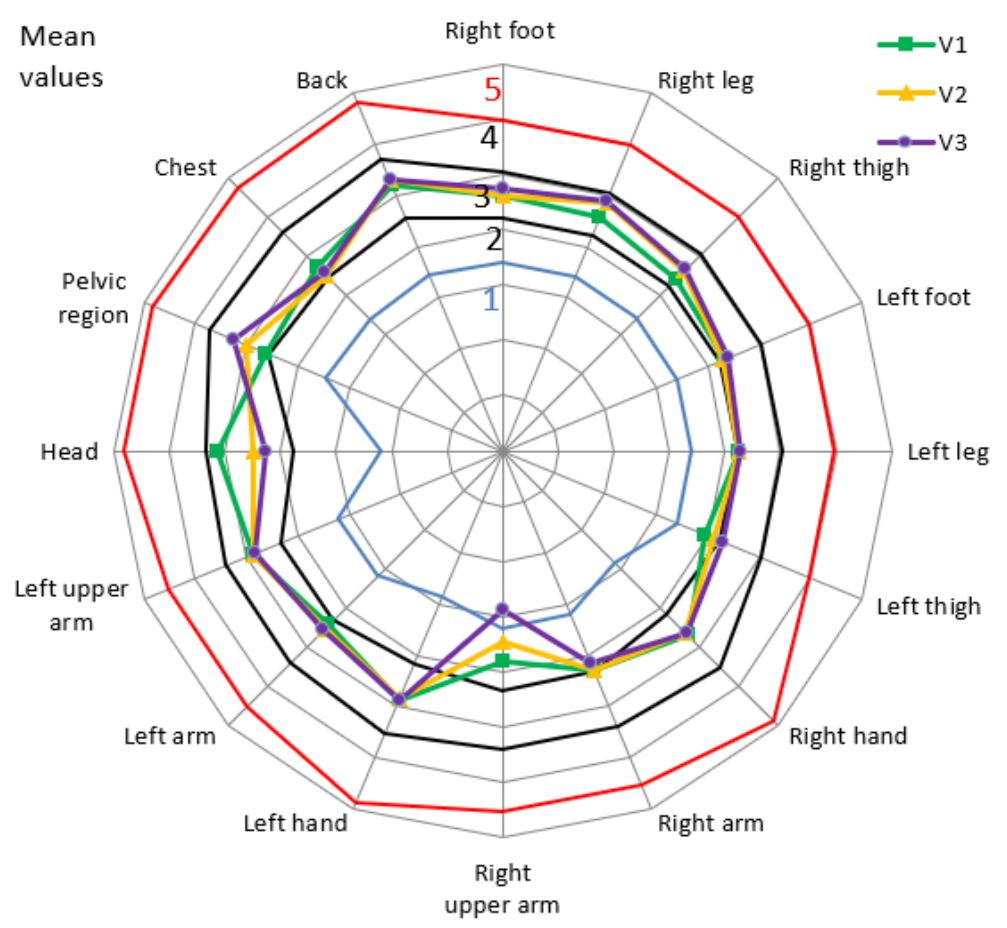

Fig. 11. Distribution of the mean $t_{e q}$ values

As it can be observed in Figure 11, the thermal manikin is assessing a high uncomfortable cold sensation for the right upper arm placed on the direction of the inlet airflow which is coming from the central diffusers. For the head, it can be seen the same behavior, for V1 the thermal sensation will be warmer than for the V2 and V3 cases. This is explained by the lower air flowrate for the V1 case. Some of the regions as the chest, the left leg, the left foot, the right arm, and the left arm are near the region of cold sensation but still in the comfortable thermal sensation zone. The $t_{e q}$ of all the other body parts are in the zone 3 which is a neutral sensation.

Figure 12 shows the percentages of thermal sensation votes (TSV) resulting from the questionnaires completed by the 9 human subjects for the three positions of the air flowrate of the ventilation/cooling system. 


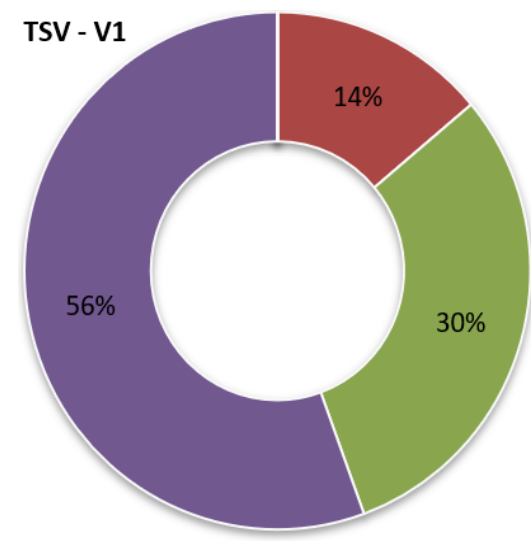

- +3 Hot

- +2 Warm

- +1 Slightly warm

- 0 Neutral

- -1 Slightly cool

- -2 Cool

- -3 Cold

a.

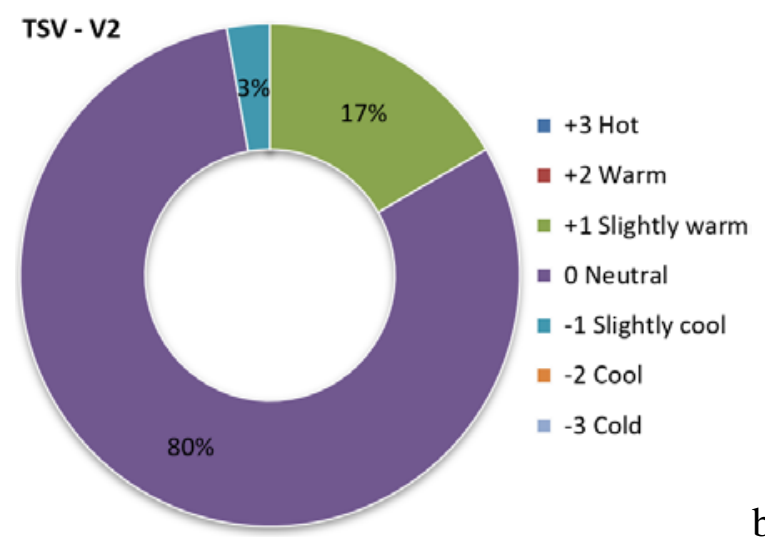

b.

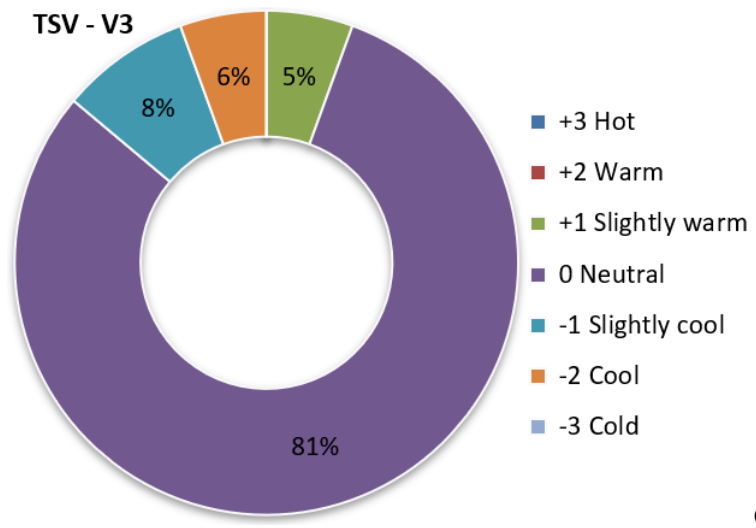

C.

Fig. 12. Percentages of thermal sensations from the questionnaires for the three velocity positions As it can be observed from this figure, for the lower air flowrate (V1), 14\% of the human subjects express a warm sensation and the general tendency for this case is to vote for the slightly warm option. For the higher air flowrate (V3), 6\% of the passenger's asses a cool sensation and the general tendency is showing a slightly cool sensation due to the higher air velocities. For the second position (V2) the majority percentages of the expressed votes are around neutral sensation. Based on the sample used in the current study, for this situation, the second air flowrate position (V2) seems to provide better comfort sensation than the other flowrates.

The values of the PMV assessed with the Comfort Sense (CS) system are shown in figure 13. In order to obtain PMV values, there were four of the variables measured with Comfort Sense probes (air velocity, air temperature, relative humidity, and operative temperature) and the other two were 
considered as follows: 1 met for metabolic rate and 0.7 clo for clothing insulation. The PMV values are presented in this manner to highlight that the place of the measurement probes is very important when thermal comfort is evaluated in a such complex and non-uniform environment.

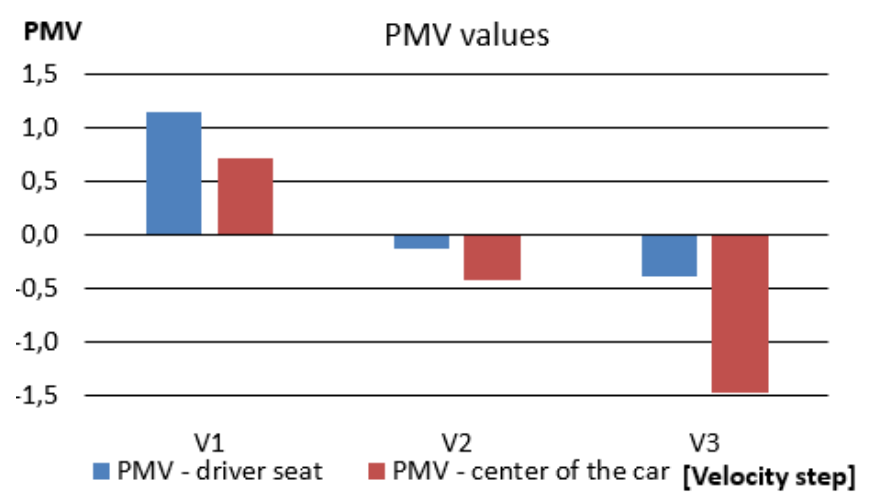

Fig. 13 PMV values in centre of the car and on the driver place for the three position of the ventilation/cooling system

In some articles it can be found that the authors placed the measurement probes in the centre of the vehicle and the resulting value was for all the environment (Lin et al. 2010; Orzechowski and Skrobacki 2016). It can be seen from figure 13 that the PMV values assessed in the two places are not similar. For the first air flowrate position (V1) it can be observed that there is a slightly warm sensation on the place of the driver while in the centre the tendency is to neutral state. This conclusion can be explained by the air flowrate from the central diffusers which is passing to the proximity of the velocity probe and cools down that region. There is also a high discrepancy that can be seen in the case of the third air flowrate position (V3) when the PMV from centre is showing a cool thermal state which is due to the high velocity of the air passing through the centre of the vehicle. For this case, the PMV index value from the driver place is in the comfort ranges.

In the second part of this chapter, the recorded values of the three standardized indexes were compared. The comparison of mean values of PMV index with TSV index values are presented in Figure 14. Both indexes use the same seven points sensation scale.

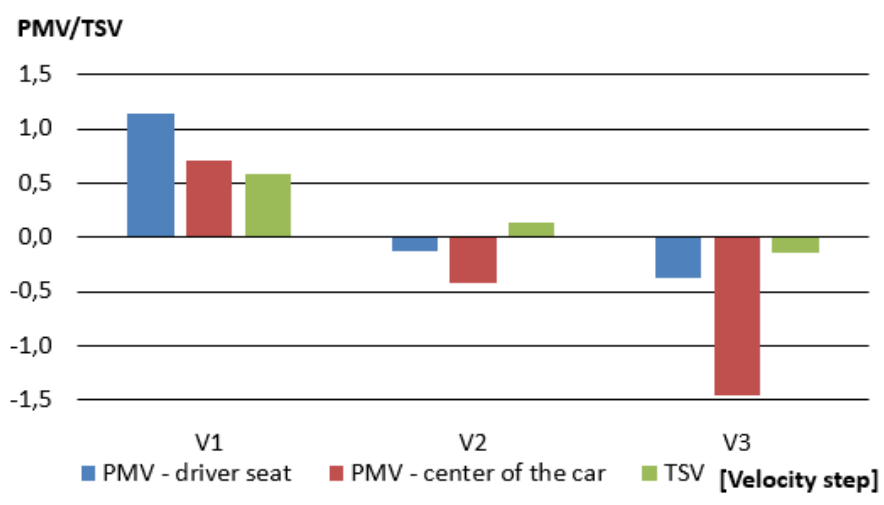

Fig. 14 Comparison between the PMV and TSV indexes 
It is obvious that the PMV values recorded on the driver place are closer to the TSV values resulting from the questionnaires, while the PMV values recorded in the centre of the vehicle are far from the TSV values. It can be seen in Figure 14 that the larger the air flowrate, the greater the difference between PMV (driver) and TSV. Once again, the importance of the measurement point is highlighted. The small differences between the results of these two indexes in the driver place may be explained by the fact that the PMV index is calculated in a single point while the TSV value is considering the sensations of each human body part.

In Table 5 there are exposed the mean values of the standardized indexes for the three ventilation/conditioning system position.

Table 5. Values of thermal comfort evaluation indexes

\begin{tabular}{|c|c|c|c|c|c|c|}
\hline \multirow{2}{*}{$\begin{array}{c}\text { Index/ } \\
\text { Velocity }\end{array}$} & Global $t_{\text {eq }}$ & TSV & $\begin{array}{c}\text { PMV - } \\
\text { driver seat }\end{array}$ & $\begin{array}{c}\text { PPD - } \\
\text { driver seat }\end{array}$ & $\begin{array}{c}\text { PMV - center of } \\
\text { the car }\end{array}$ & $\begin{array}{c}\text { PPD - } \\
\text { center of the car }\end{array}$ \\
\cline { 2 - 6 } V1 & {$\left[{ }^{\circ} \mathrm{C}\right]$} & {$[-]$} & {$[-]$} & {$[\%]$} & {$[-]$} & {$[\%\}$} \\
\hline V2 & $\begin{array}{c}22.76 \text { (cold but } \\
\text { comfortable) }\end{array}$ & $\begin{array}{c}0.58 \\
\text { (slightly } \\
\text { warm) }\end{array}$ & $\begin{array}{c}1.15 \\
\text { (warm) }\end{array}$ & $32.8 \%$ & $\begin{array}{c}0.72 \text { (slightly } \\
\text { warm) }\end{array}$ & $15.9 \%$ \\
\hline V3 & $\begin{array}{c}22.80 \text { (cold but } \\
\text { comfortable) }\end{array}$ & $\begin{array}{c}0.14 \\
\text { (neutral) }\end{array}$ & $\begin{array}{c}-0.12 \\
\text { (neutral) }\end{array}$ & $5.3 \%$ & -0.41 (neutral) & $8.5 \%$ \\
\hline
\end{tabular}

For all the three studied cases, the thermal manikins show the same thermal sensation, cold but comfortable. Also, the TSV values are remaining within the neutral ranges. Thermal sensations resulting PMV index values in the driver place are similar to the other indexes, excepting V1 flow rate position where a warm thermal sensation was found. It was previously mentioned that this difference might be from the fact that PMV is a global evaluation index, while the other two methods consider the local sensations of each body part. A global value of the $t_{e q}$ might be not very much relevant, given the principle of measurement using the thermal manikin. At the same time, a global TSV reflects a pure subjective perception, knowing that interpersonal differences might occur for each body part local sensation and its corresponding weight to the global TSV (Zhang et al. 2010).

Most of the studies dedicated to buildings and using human subjects in dynamic states have been conducted in climatic chambers, and only few of them have been validated in real or in situ conditions. However, an accurate prediction of people's thermal perception in dynamic state does not yet exist and PPD and PMV models do not accurately reflect people's thermal perception in such an unsteady state such as passengers who are experiencing "alliesthesia” of the cool indoor environment and this can be an explanation of why they are not so dissatisfied as the measurements have proved. Generally speaking, the sensations of coldness are amplified in the response of the Comfort Sense system, in comparison with the TSV and the thermal manikin. This result is a confirmation of 
previous analysis carried out in another typology of environment (Buratti and Ricciardi 2009).

It can be noted here that subjective methods quantify the response of people to an environment using some subjective scales as it was previously shown. Such scales are derived via statistical methods from psychological responses of large samples of subjects. These responses are relevant to the physiological phenomena of interest such as the thermal sensation in contact with a specific environment. Thus, it is important to know the properties of the scales in order to correctly interpret the results. Scales of thermal sensation (hot or cold), preference, comfort and stickiness are often used in thermal comfort assessment. The main advantages of the subjective methods are that they are relatively simple to put in practice and they are directly related to the psychological phenomenon, but their important disadvantage is that the responses may interfere with what it is measured. A possible interference of the procedure itself with the answers of the subjects must be considered always when analysing the TSV results.

\section{Conclusions}

This paper is focused on the transient non-uniform environment inside the automobile passenger compartment. Determination of the vehicle occupants thermal comfort is very complicated due to the transient nature and non-uniformity of the vehicle interior. Furthermore, the actual standard is proposing three evaluation indexes and it was developed for steady state and for controlled conditions and some of the indexes are not adapted to this complex environment.

The values obtained for the three standardized indexes in term of thermal comfort, in a vehicle passenger in summer season have been compared in this article.

The results demonstrates that the mean values calculated using PMV/PPD model in a single point with Comfort Sense equipment are very different from the TSV mean values resulting from questionnaires survey with human subjects while the $t_{e q}$ index calculated with an advanced thermal manikin is closer to the TSV comfort votes results. This conclusion might be explained because both the TSV and $t_{e q}$ take into account the sensation for each body part at the local level. In order to have a correct evaluation of the thermal comfort in non-uniform and transient environments like the vehicle cabins, it is not enough to measure parameters in a single point and to extrapolate this value in all ambient. The main conclusion is that the PMV/PPD indexes are not very well adapted to the vehicle environment. At the same time a global TSV reflects a pure subjective perception, knowing that interpersonal differences might occur for each body part local sensation and its corresponding weight to the global TSV.

The final suggestion is that the PMV/PPD model should not be used for non-uniform environment like an automobile. The high velocities from the air diffusers are beyond the limits of

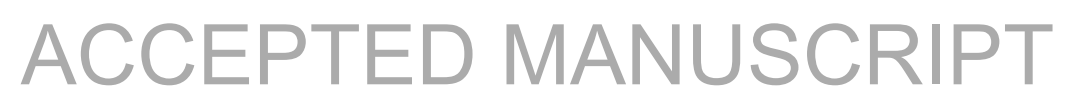


those models. The thermal manikin and complementary measurements could be used along with subjective studies in this matter.

The study is part of a larger investigation that takes also into account other factors such as the influence of the geometry of the air diffusers on the thermal environment inside the cabin, through experimental and numerical approaches. Regarding to the experimental study presented in this article, a short-term perspective is to complete it during winter conditions using both the developed thermal manikin and human subjects.

\section{Acknowledgment}

This work was supported by the grant Innovative system to extend the range of electric vehicles at improved thermal comfort - XTREME, PN-III-P2-2.1-PED2019-4249.

\section{Nomenclature}

$\begin{array}{ll}\text { PMV } & \text { Predicted Mean Vote } \\ \text { PPD } & \text { Predicted Percentage of Dissatisfied } \\ \text { TSV } & \text { Thermal Sensation Vote } \\ t_{\text {eq }} & \text { Equivalent temperature }\end{array}$

\section{Bibliography}

Alahmer, A., A. Mayyas, A.-A. Mayyas, M.-A. Omar and D. Shan. 2011. Vehicular thermal comfort models; a comprehensive review. Applied Thermal Engineering 31(6-7): 9951002

Barna, E., and L. Bánhidi. 2012. Combined effect of two local discomfort parameters studied with a thermal manikin and human subjects. Energy and Buildings 51: 234-241.

Bode, F., I. Nastase, P. Danca, and A. Meslem. 2017. The influence of the Inlet angle of vehicle air diffuser on the thermal comfort of passengers. In International Conference on Energy and Environment. 442 - 446. Bucharest: IEEE

Bonnett. R. 2006. International Encyclopedia of Ergonomics and Human Factors - 2nd ed. Boca Raton: CRC Press.

Buratti C., and P. Ricciardi. 2009. Adaptive analysis of thermal comfort in university classrooms: correlation between experimental data and mathematical models. Build Environ 44: 674-687.

Causone, F., F. Baldin, B.-W. Olsen, and S.-P. Corgnati 2010. Floor heating and cooling combined with displacement ventilation: Possibilities and limitations. Energy and Buildings 42(12): 2338-2352

Cheong, K. W. D., W. J. Yu, R. Kosonen, K. W. Tham and S. C. Sekhar 2006. Assessment of thermal environment using a thermal manikin in a field environment chamber served by displacement ventilation system. Building and Environment 41(12): 1661-1670. 
Danca, P. A. 2018 Ventilation strategies for improving the indoor environment quality in vehicles. PhD diss., Université Rennes 1; Université Technique de Constructions Bucarest.

Danca, P., F. Bode, I. Nastase, and A. Meslem 2017. On the Possibility of CFD Modeling of the Indoor Environment in a Vehicle. Energy Procedia 112: 656-663.

Danca, P., F. Bode, I. Nastase, and A. Meslem. 2018. CFD simulation of a cabin thermal environment with and without human body - thermal comfort evaluation. E3S Web Conf. 32: 01018.

Danca, P., I. Nastase, F. Bode, C. Croitoru, A. Dogeanu, and A. Meslem. 2019. Evaluation of the thermal comfort for its occupants inside a vehicle during summer. IOP Conf. Ser.: Mater. Sci. Eng. 595012027

Dantec Dynamics. 2019 Comfort Sense, Thermal Comfort Measurement Solution. Last Modified available on 2019. Accessed February 10. 2021 https://www. dantecdynamics.com/wpcontent/uploads/2019/10/0553_v1_SS_ComfortSense.pdf

Dehne, T., P. Lange, A. Volkmann, D. Schmeling, M. Konstantinov, and J. Bosbach 2018. Vertical ventilation concepts for future passenger cars. Building and Environment 129: 142-153

Feher, S. 1993. Thermoelectric Air Conditioned Variable Temperature Seat (VTS) and Effect Upon Vehicle Occupant Comfort, Vehicle Energy Efficiency, and Vehicle Environmental Compatibility. In Vehicle Thermal Management Systems Conference Proceedings, 254 - 263. Warrendale: Society of Automotive Engineers.

Fojtlín, M., J. Fiser, J. Pokorny, A. Povalac, T. Urbanec and M. Jicha 2017. An innovative HVAC control system: Implementation and testing in a vehicular cabin. Journal of Thermal Biology 70: 64-68.

Grundstein, A., V. Meentemeyer and J. Dowd. 2009. Maximum vehicle cabin temperatures under different meteorological conditions. Int J Biometeorol 53: 255-261.

ISO 10551. 1995. Ergonomics of the thermal environment - Assessment of the influence of the thermal environment using subjective judgement scales, ISO 10551.

ISO 14505-1. 2007. Ergonomics of the thermal environment - Evaluation of thermal environments in vehicles Part 1: Principles and methods for assessment of thermal stress. ISO 14505-1:2007.

ISO 14505-2. 2006. Ergonomics of the thermal environment - Evaluation of thermal environments in vehicles - Part 2: Determination of equivalent temperature ISO 145052:2006.

ISO 14505-3. 2006. Ergonomics of the thermal environment -Evaluation of thermal environments in vehicles Part 3: Evaluation of thermal comfort using human subjects. ISO 14505-3:2006.

Konstantinov, M., and C. Wagner. 2016. Numerical Simulation of the Thermal Comfort in a Model of a Passenger Car Cabin, Cham: Springer International Publishing

Krajík, M., A. Simone and B. W. Olesen. 2012. Air distribution and ventilation effectiveness in an occupied room heated by warm air. Energy and Buildings 55: 94-101

Lee, D. W. 2015. Impact of a three-dimensional air-conditioning system on thermal comfort: An experimental study. International J ournal of Automotive Technology 16(3): 411416.

Lin, T.-P., R.-L. Hwang, K.-T. Huang, C.-Y. Sun, and Y.-C. Huang. 2010. Passenger thermal perceptions, thermal comfort requirements, and adaptations in short- and long-haul vehicles. International J ournal of Biometeorology 54(3): 221-230

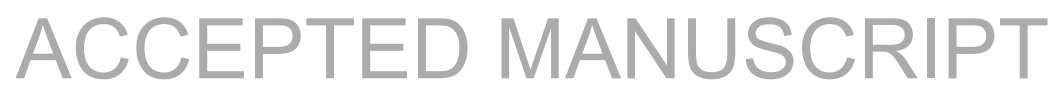


Mao, Y., J. Wang, and J. Li. 2018. Experimental and numerical study of air flow and temperature variations in an electric vehicle cabin during cooling and heating. Applied Thermal Engineering 137: 356-367

Melikov, A., T. I vanova, and G. Stefanova 2012. Seat headrest-incorporated personalized ventilation: Thermal comfort and inhaled air quality. Building and Environment 47: 100-108.

Orzechowski, T., and Z. Skrobacki. 2016. Evaluation of thermal conditions inside a vehicle cabin. EPJ Web of Conferences 114: 02085.

Psikuta, A., J. Allegrini, B. Koelblen, A. Bogdan, S. Annaheum, N. Martinez, D. Derome, J. Carmeliet, and R. M. Rossi. 2017. Thermal manikins controlled by human thermoregulation models for energy efficiency and thermal comfort research - A review. Renewable and Sustainable Energy REviews 78: 1315-1330.

Rugh, J. P., and D. Bharathan 2005. Predicting Human Thermal Comfort in Automobiles SAE Transactions 114: 2508-516

Shin, Y., G. Im, K. Yu, and H. Cho. 2017. Experimental study on the change in driver's physiological signals in automobile HVAC system under Full load condition. Applied Thermal Engineering 112: 1213-1222.

Ursu. I., D. Guta, C. Croitoru, P. Danca, and I. Nastase. 2018. Advanced Thermal Manikin Prototype with Neuro-fuzzy Control System. In Proceedings of the 4th International Conference On Building Energy \& Environment ed. K. Inthavong, C. P. Cheung, G. Yeoh and J . Tu. 542 - 546, Melbourne: Conference On Building Energy \& Environment - COBEE2018, Melbourne Australia

Walgama, C., S. Fackrell, M. Karimi, A. Faraj, and G. W. Rankin. 2006. Passenger Thermal Comfort in Vehicles - A Review. J ournal of Automobile Engineering 220(5): 543-562.

Zhang, H., E. Arens, C. Huizenga, and T. Han. 2010. Thermal sensation and comfort models for non-uniform and transient environments: Part I: Local sensation of individual body parts. Building and Environment 45(2): 380-388.

Zhou, X., D. Lai, and Q. Chen. 2019. Experimental investigation of thermal comfort in a passenger car under driving conditions. Building and Environment 149: 109-119. 